\title{
Damage Detection of Carbon Face Sheet Nomex Sandwich Composites with Image Processing Technique
}

\author{
Ibrahim Demirci*1, Ismail Saritas ${ }^{2}$
}

\begin{abstract}
Submitted: 24/11/2021 Accepted : 27/12/2021
Abstract: In this study, the low-velocity impact behavior of carbon face sheet Nomex honeycomb composites at repeated and increasing energy levels was investigated. Contrary to the usual method, a different method was used to analyze the damage that occurred after the low-velocity impact tests. Image-processing methods have been applied in many fields. It is thought that image processing methods will yield successful results in a detailed examination of the damage in composite materials. In addition, the detection and detailed examination of barely visible damage is also of vital importance in determining the life of composites. An ultrasonic underwater c-scan device was used to obtain damage images. Ultrasonic c-scan, which is a non-destructive testing method, is frequently used to determine damage locations and sizes in aviation areas. The use of ultrasonic systems is more advantageous in terms of speed and accuracy than other methods. An image processing method was developed to calculate the damaged areas by obtaining images. The main structure of image processing is the $\mathrm{L}^{*} \mathrm{a} * \mathrm{~b} *$ color feature space of pixels. When the $\mathrm{C}$-scan images were examined, the image colors were red, blue, and green. In the $\mathrm{L}^{*} \mathrm{a}^{*} \mathrm{~b}$ method, it was observed that the blue-colored areas, which are the damaged areas, were successful in separating them from the other undamaged areas. A Gaussian filter followed by a binary method was used to determine the last damage areas, and the damage areas were calculated.
\end{abstract}

Keywords: Carbon Face Sheet Nomex Sandwich, Ultrasonic C-Scan, Image Processing, Low-Velocity Impact Test, L*a*b*

This is an open access article under the CC BY-SA 4.0 license. (https://creativecommons.org/licenses/by-sa/4.0/)

\section{Introduction}

Honeycomb sandwich composite materials are used in automotive, aerospace and many important fields due to their high strength and high specific energy absorption [1-5]. Lowvelocity impact response of tube-reinforced honeycomb sandwich structure]. Sandwich composite materials are increasingly used in a wide variety of engineering structures, including helicopter rotor blades, aircraft fins and fairings, ship's deck braces and bulkheads, rocket infrastructures, and space structures. The lightness-hardness ratios of sandwich structures create a good material structure for aerospace applications [6]. Almost all structures used in military helicopters such as the Eurocopter Tiger and NH90 are made of sandwich materials [7]. The core structures of sandwich composite materials generally consist of aluminium and Nomex ${ }^{\circledR}$ honeycombs, synthetic PVC, aluminium foams, balsa wood and corrugated materials. The materials that make up the core part of the sandwich composite structure have lower strength than the face sheet materials [8]. Invisible damage can occur in sandwich composite structures at low energy impact energies. Even minor damages cause a decrease in the strength of sandwich composite structures used in important areas [9]. In honeycomb composite structures, the side length of the honeycomb cell, height of the honeycomb core, and geometric

${ }^{1}$ Department of Mechatronics Engineering, Faculty of Technology, Selcuk University, Konya, Türkiye, ORCID ID : 0000-0002-6808-8550

${ }^{2}$ Department of Electrical and Electronics Engineering, Faculty of

Technology, Selcuk University, Konya, Türkiye,

ORCID ID : 0000-0002-5743-4593

* Corresponding Author Email: ibrahim.demirci@selcuk.edu.tr structure of the honeycomb structure are the factors that directly affect the impact resistance of the sandwich composite material [10].

Damage that cannot be detected during the visual inspection of composite sandwich structures may cause more serious damage in the future. Damage to the composites are evaluated in two categories. These are visible impact damage (VID) and barely visible impact damage (BVID). sandwich composite panels must be designed to withstand low-energy impact damage (BVID) and maximum load. BVID is defined as damage that cannot be seen at a distance of $1.5 \mathrm{~m}$ during routine inspection or has an indentation size between $0.25 \mathrm{~mm}$ and $0.5 \mathrm{~mm}$ [11]. BVID is accepted as the damage tolerance of sandwich structures. Nondestructive testing (NDT) is effective for solving this problem [12].

Ultrasonic c-scan scanning is one of the best non-destructive testing methods for examining and characterizing damage in sandwich composite materials [13]. Ultrasonic c-scan scanning technique is quite simple and useful [14]. Produced commercial poly (lactic acid) (PLA)-based fully biolaminated structures and composites were produced from these laminated structures by pressing method. Low-speed impact tests were performed on the produced composites at energy levels of $2 \mathrm{~J}, 5 \mathrm{~J}, 10 \mathrm{~J}, 12 \mathrm{~J}$ and 15 J. Ultrasonic C-Scan non-destructive testing was applied to the damages resulting from the experiments. The dimensions and shapes of the damages formed by the $\mathrm{C}$ scan method were analysed. Images were taken from both the impact test surface and the other surface. The dimensions, shape and indentation depth of the damage were determined. As a result of the 
determination of the indentation depth, the threshold energy was calculated for the damage to occur [14,15]. An advanced technique using image processing has been developed for the automated ultrasonic inspection of composite materials, such as glass/carbon fiber reinforced polymers. Owing to the applied technique, it is capable of identifying embedded anomalous features in the composite through image filtering and segmentation applied to ultrasonic C-scan images. This study shows the results performed on two composite samples with simulated delamination defects. In this study, different filtering and thresholding algorithms were evaluated and compared in terms of their effectiveness in damage detection. Accuracies of less than $3 \mathrm{~mm}$ and $1.11 \mathrm{~mm}$ were obtained for defect size and depth. The results demonstrate the feasibility of the proposed technique for accurate defect localization and characterization of composite materials [15]. W. post et al. In their study, they conducted a comparative study on the monitoring of delamination healing using non-destructive techniques and destructive compression testing in CFRP-ionomer sandwich composites. The occurrence and healing of delamination were monitored by the frequency shift of the local defect resonance (LDR) in both airand water-coupled ultrasonic C-scan experiments. It has been determined that the LDR approach can be used to detect earlystage delamination. Ultrasonic $\mathrm{C}$-scan techniques were also very effective in determining the degree of healing in the final stages of the repair process [16].

The visualization and interpretation of the damage in sandwich composite materials requires attention. Analysing C-scan images is often dependent on expert experience. Damage analysis of sandwich composite materials, which are used in many vital areas such as aviation, requires precision. Because of image-processing techniques, human errors can be minimized. In addition, the progression of damaged areas under increased impact energy can be determined using image-processing techniques. In our study, low-speed impact testing at increasing and repetitive energy levels was performed on carbon fiber face sheet Nomex sandwich composites. Energy levels were determined as $5+0 \mathrm{j}, 5+5 \mathrm{j}, 5+10$ $\mathrm{j}, 5+15 \mathrm{j}$, and $5+20 \mathrm{j}$. The low-velocity impact test was conducted at these energy levels to detect the growth of damaged areas. Damage images were obtained using the c-scan scanning method for samples that were subjected to low-velocity impact tests. To determine the growth of the damaged areas more precisely, an image processing method was applied, and the damage areas were calculated.

\section{MATERIAL and METHOD}

\subsection{Production of Sandwich Composite Plates}

Composite plates can be produced in three different ways. These are autoclave, vacuum infusion, and hot-press techniques. The hot press technique has come to the fore. In the literature, it was determined that the average fracture toughness of the samples produced by hot pressing was approximately 1.6 times higher than that of the samples produced by autoclave. While the fracture toughness of the samples produced by autoclave was 564 and $527 \mathrm{~J} / \mathrm{m} 2$, the fracture toughness of the composites produced by hot pressing was found to be approximately $783 \mathrm{~J} / \mathrm{m}^{2}[17,18]$. In this study, carbon-fiber Nomex sandwich plates were fabricated. The sandwich composite plate Nomex honeycomb core has four layers of carbon fiber fabric in each of the lower face layer and upper face layer. The carbon fibers used were Kordsa company $245 \mathrm{gr} / \mathrm{m}^{2} 2 \times 2$ twill fiber fabrics used for aviation applications. The Nomex honeycomb were also supplied by the Fibermax company and has a core diameter of $3.2 \mathrm{~mm}$ and a thickness of $10 \mathrm{~mm}$. The carbon fiber face sheet Nomex sandwich composite and carbon fiber face sheet Nomex sandwich composite production by the hot press method is shown in the figure 1 .
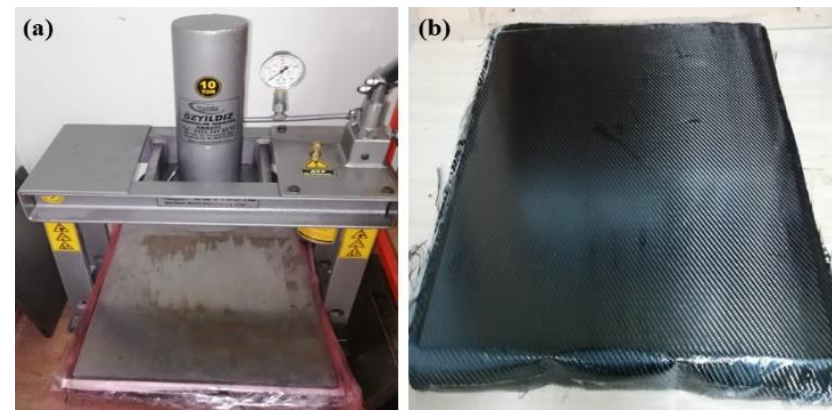

Figure 1. (a) Production of carbon fiber face sheet Nomex sandwich composite plate by hot press method, (b) Carbon fiber face sheet Nomex sandwich composite plate

Low-velocity impact experiments were performed using the dynamic test setup shown in Figure 2. 100x150 mm impact samples were used in low-velocity impact tests. Low-velocity impact tests were performed according to the ASTM D7136/7136M standards. The impact energy levels of the sandwich composite plates were calculated mathematically using the $\mathrm{Z}=\mathrm{a}+\mathrm{bi}$ formula. Using this formula, it is possible to mathematically increase the energy levels in repeated experiments. where a is the energy level required for the first damage to occur and is determined as $5 \mathrm{j}$. The value of ' $\mathrm{i}$ ' for all the experiments was $5 \mathrm{j}$. The value we express as $\mathrm{j}$ in the formula is the value that allows the initial damage to grow in repeated damages, and it has been determined as $5 \mathrm{j}$. The $\mathrm{k}$ in the formula is the coefficient and is determined as $0,1,2,3$, and 4 . When the determined values were combined in the formula, our lowvelocity impact experiments were carried out at energy levels $Z=$ $5+0 j, Z=5+5 j, Z=5+10 j, Z=5+15 j, Z=5+20 j$. The lowvelocity impact tester has a pneumatic impact protection system that prevents repetitive impacts after the first impact. The impactor had a radius of $12 \mathrm{~mm}$ with a spherical half tip and a mass of $5.6 \mathrm{~kg}$. The data recording system in the test stand can transmit the force signal at a sampling rate of $25 \mathrm{kHz}$. Lowvelocity impact test were carried out in Konya Technical University, Mechanical Engineering Department Laboratory. The low-velocity impact test device and bracing of the composite specimens are shown in the figure 2.
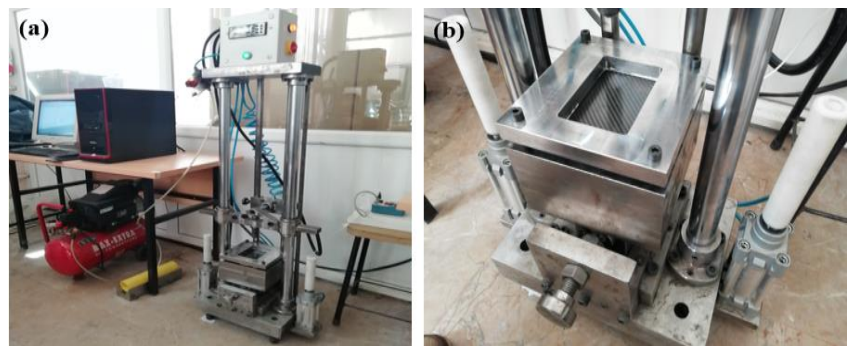

Figure 2. (a) Low-velocity impact test device, (b) Bracing of composite specimens

\subsection{Ultrasonic C-Scan}

Ultrasonic C-scan is a highly effective test mechanism for corrosion mapping and defect detection. The transducer emits ultrasonic sound waves and analyses the transmitted signal to inspect the component. There are many formats available for 
collecting and displaying ultrasonic test data, such as A-scan, Bscan, and C-scan. While other mechanisms provide the most basic $2 \mathrm{D}$ plot of the ultrasonic wave, the $\mathrm{C}$-scan ultrasonic test displays the data along with the depth or amplitude of the wave. Data presented at high resolution and with different colour patterns increase the accuracy of damage detection in components. After the low-speed impact experiments, damage images of the samples were obtained at each energy level using the ultrasonic underwater C-scan scanning device. An ultrasonic underwater c-scan scanning device was manufactured by a CRD industrial company. The damaged areas in the obtained images were determined using the image processing method, and the damage growth was controlled by increasing the energy levels. Damaged areas are shown in intense blue on the scan images. The scattered blue spots outside the damaged area are not damaged area. These regions indicate a porous structure originating from the structure of the honeycomb Nomex material. The features of the ultrasonic underwater c-scan device are given below.

Prob; 2 ultrasonic probes, $1 \mathrm{PE}$ and 1 TT connection.

The operating frequency range is at least $0.5 \mathrm{MHz}$ to $25 \mathrm{MHz}$.

Available frequency filters at least $(-3 \mathrm{~dB}): 0.5-6 \mathrm{MHz}, 0.5-$ $10 \mathrm{MHz}, 0.5-15 \mathrm{MHz}, 0.5-25 \mathrm{MHz}, 1-6 \mathrm{MHz}, 1-10 \mathrm{MHz}, 1-$ $15 \mathrm{MHz}, 1-25 \mathrm{MHz}, 2-6 \mathrm{MHz}, 2-$ It is $10 \mathrm{MHz}, 2-15 \mathrm{MHz}, 2-$ $25 \mathrm{MHz}, 4-6 \mathrm{MHz}, 4-10 \mathrm{MHz}, 4-15 \mathrm{MHz}, 4-25 \mathrm{MHz}$.

Ultrasonic data acquisition unit; The unit has RF, Positive, Negative, filter indication. The Pulse Repeat Frequency is a maximum of $10 \mathrm{Khz}$. The amount of gain is at least $89 \mathrm{~dB}$

$\mathrm{C}$-scan images were obtained using an ultrasonic underwater Cscan device at Selcuk University, Faculty of Technology, Mechatronics Engineering Laboratory.

The ultrasonic underwater C-scan device is shown in the figure 3.

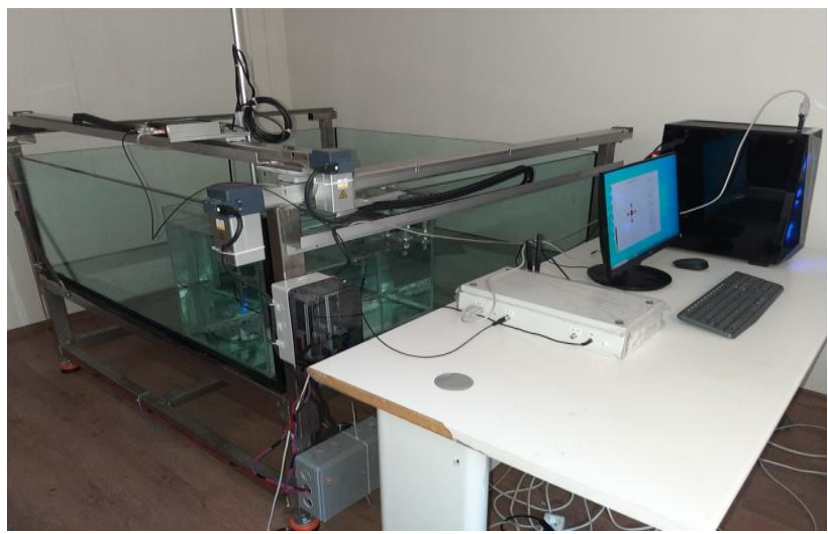

Figure 3. Ultrasonic underwater c-scan

\subsection{Image Processing}

The first step of the image processing process is to convert the RGB images obtained from the C-Scan device to $1^{*} \mathrm{a} * \mathrm{~b}$ images. $1 * a * b *$ colour values are the most commonly used method for measurement and colour communication. $\mathrm{L}^{*} \mathrm{a}^{*} \mathrm{~b}^{*}$ values are designed close to human eye perception. It defines all the colours that the human eye can perceive and is used in many areas around the world. $\mathrm{L}^{*} \mathrm{a}^{*} \mathrm{~b}^{*}$ colour values, 3-dimensional colour coordinates are listed below:

$\mathrm{L}^{*}$ - Brightness of the image: Values are in the range of $[0,100]$, 0 indicates black, and 100 indicates white. As $L^{*}$ increases, the colours become brighter.

$a^{*}$ - The amount of red or green tones in the image. A large positive $a^{*}$ value corresponds to red/magenta. A large negative $a^{*}$ value corresponds to green. Although there is no single range for $a^{*}$, the values are usually in the range $(-100,100)$ or $(-128,127)$. $b^{*}$ - The amount of yellow or blue tones in the image. A large positive $b^{*}$ value corresponds to yellow. A large negative $b^{*}$ value corresponds to blue. Although there is no single range for $b^{*}$, the values are usually in the range $(-100,100)$ or $(-128,127)$ [19-21].

In this method, three different images were obtained: $1^{*}, a^{*}, b^{*}$ The next steps were performed for these pictures. After $\mathrm{L}^{*} \mathrm{a} * \mathrm{~b}$ treatment, Gaussian filter was applied to better define the damaged regions and to eliminate colour confusion in the nondamaged regions. Damage areas appeared more clearly in the images when the Gaussian filter was applied. The last step before the field calculation is the binary process. With this process, the damaged areas and non-damaged areas are completely separated from each other as white and black. After the binary process, the areas of the damaged areas were calculated. Image processing toolbox of MATLAB R2020b has been used for this study. The image processing stages are shown in the figure 4 .

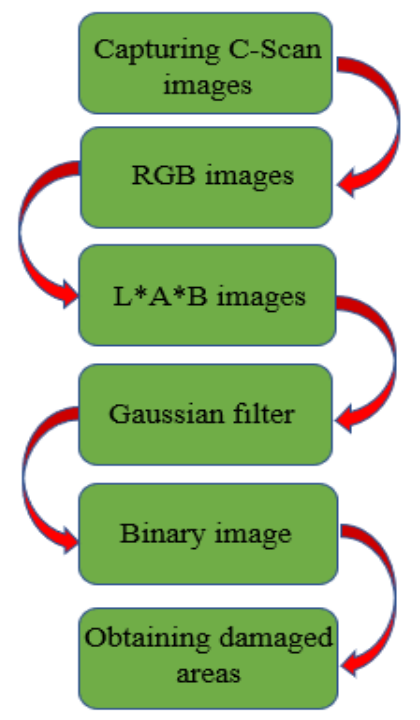

Figure 4. Image processing steps of carbon fiber face layer nomex sandwich composites

\section{Result and Discussion}

Damage images of the carbon fiber face sheet Nomex sandwich composite samples after impact were obtained using an underwater ultrasonic C-scan device. When the C-scan images were examined, it was observed that the damaged areas were intense blue areas. The undamaged areas are green areas, and the blue dotted areas within these areas are the spaces originating from the Nomex honeycomb. C-Scan, L*a*b, Gaussian filter, and binary images are given at $5+0 \mathrm{j}, 5+5 \mathrm{j}, 5+10 \mathrm{j}, 5+15 \mathrm{j}$, and $5+20 \mathrm{j}$ energy levels.

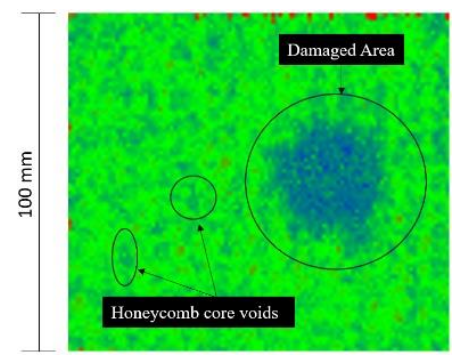

Figure 5. C-scan images of carbon fiber face sheet nomex sandwich samples at $5+0 \mathrm{j}$ energy levels 


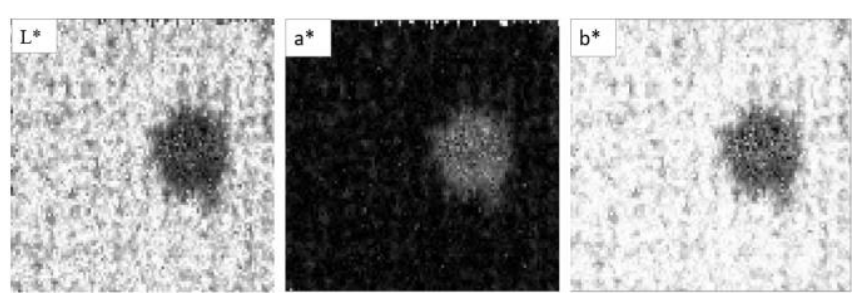

Figure 6. L*a*b images of carbon fiber face sheet Nomex sandwich samples at 5+0 j impact energy levels

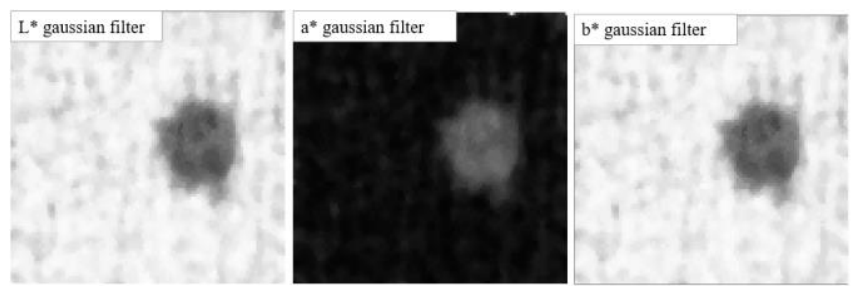

Figure 7. Gaussian images of carbon fiber face sheet Nomex sandwich samples at 5+0 $\mathrm{j}$ impact energy levels
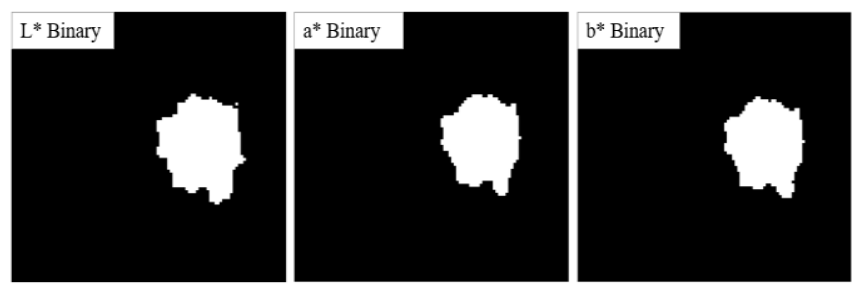

Figure 8. Binary images of carbon fiber face sheet Nomex sandwich samples at $5+0 \mathrm{j}$ impact energy levels

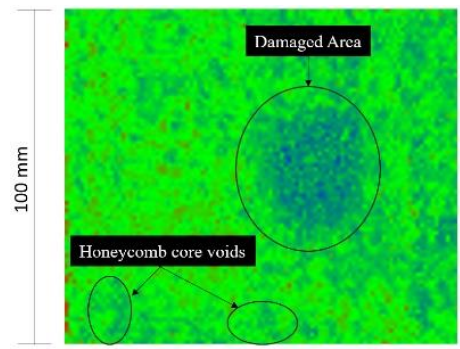

Figure 9. C-scan images of carbon fiber face sheet nomex sandwich samples at $5+5 \mathrm{j}$ energy levels

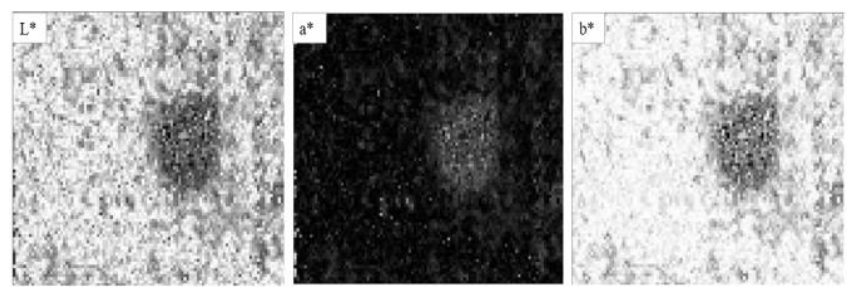

Figure 10. $L * a * b$ images of carbon fiber face sheet Nomex sandwic samples at 5+5 j impact energy levels
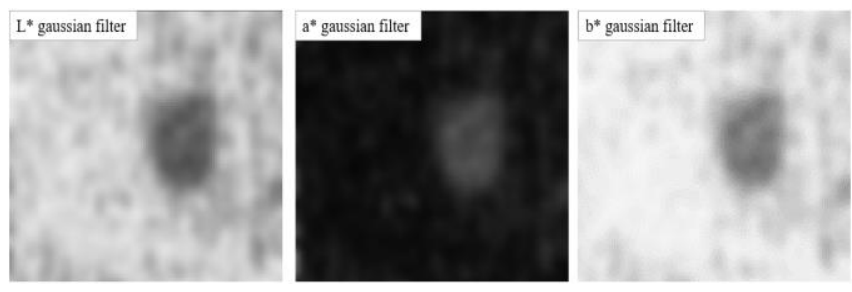

Figure 11. Gaussian images of carbon fiber face sheet Nomex sandwich samples at $5+5 \mathrm{j}$ impact energy levels
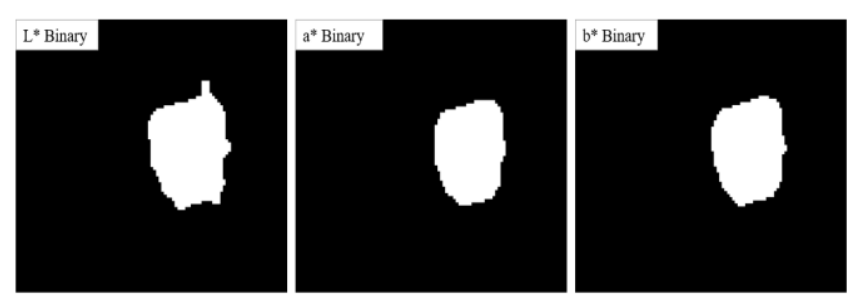

Figure 12. Binary images of carbon fiber face sheet Nomex sandwich samples at $5+5 \mathrm{j}$ impact energy levels

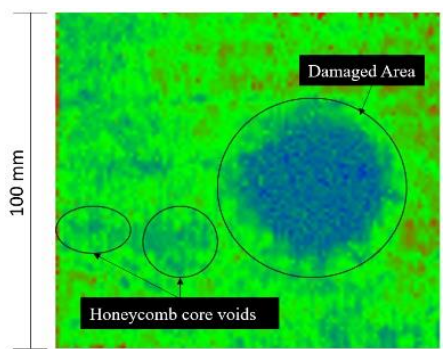

Figure 13. C-scan images of carbon fiber face sheet Nomex sandwich samples at $5+10 \mathrm{j}$ energy levels
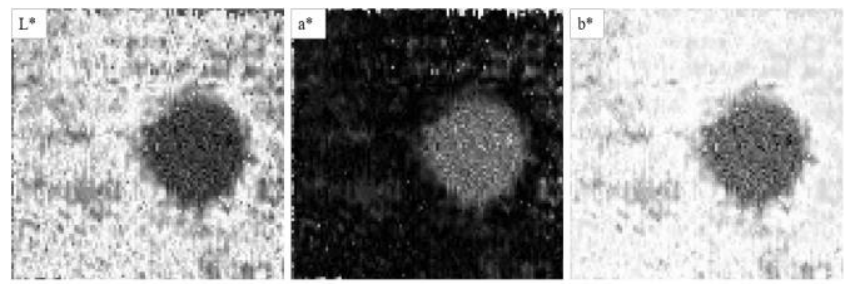

Figure 14. $\mathrm{L} * \mathrm{a} * \mathrm{~b}$ images of carbon fiber face sheet Nomex sandwich samples at 5+10 $\mathrm{j}$ impact energy
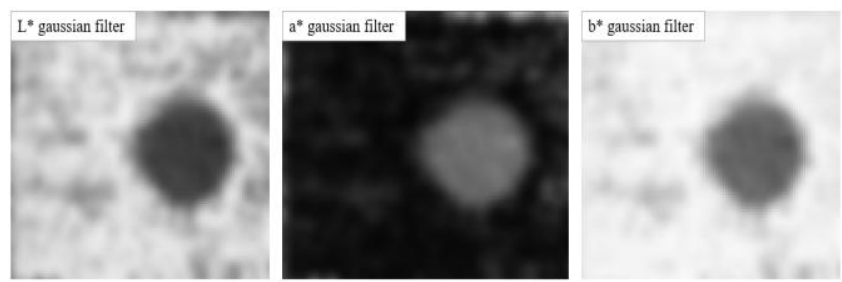

Figure 15. Gaussian images of carbon fiber face sheet nomex sandwich samples at $5+10 \mathrm{j}$ impact energy levels
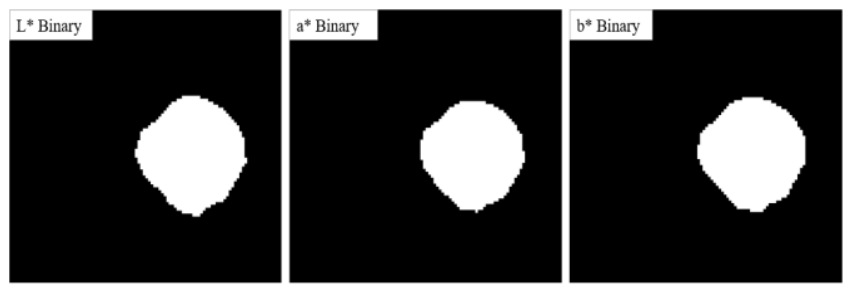

Figure 16. Binary images of carbon fiber face sheet Nomex sandwich samples at 5+10 j impact energy levels

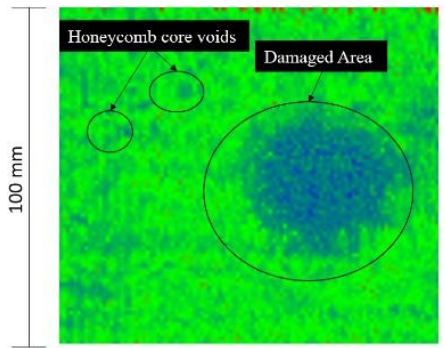

Figure 17. C-scan images of carbon fiber face sheet Nomex sandwich samples at $5+15 \mathrm{j}$ energy levels 


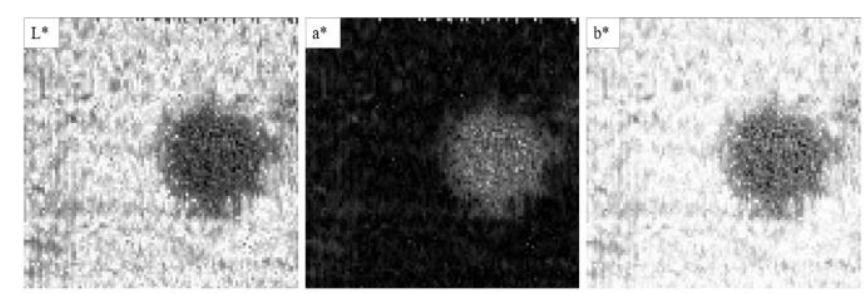

Figure 18. $\mathrm{L} * \mathrm{a} * \mathrm{~b} *$ images of carbon fiber face sheet Nomex sandwich samples at $5+15 \mathrm{j}$ impact energy

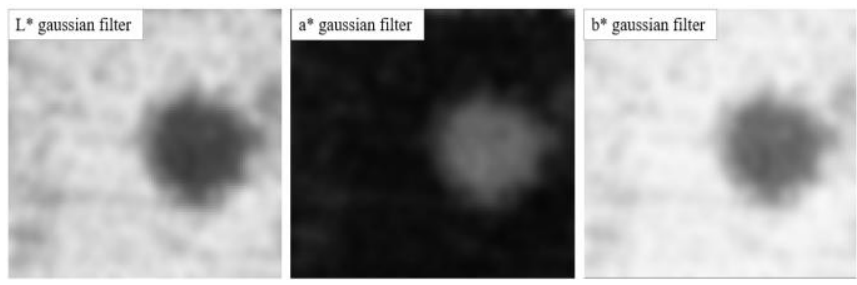

Figure 19. Gaussian images of carbon fiber face sheet Nomex sandwich samples at $5+15 \mathrm{j}$ impact energy levels
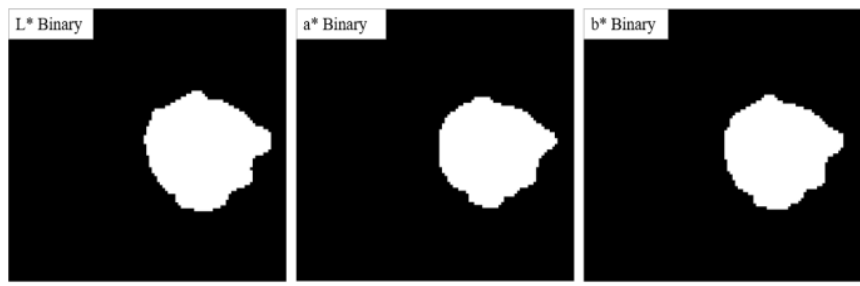

Figure 20. Binary images of carbon fiber face sheet nomex sandwich samples at $5+15 \mathrm{j}$ impact energy levels

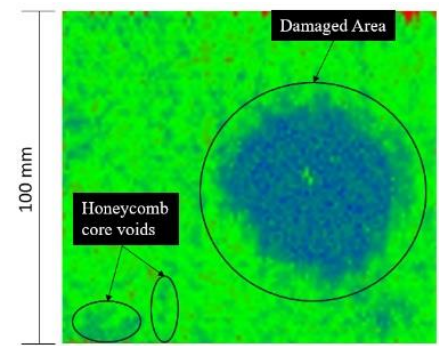

Figure 21. C-scan images of carbon fiber face sheet nomex sandwich samples at $5+20 \mathrm{j}$ energy levels
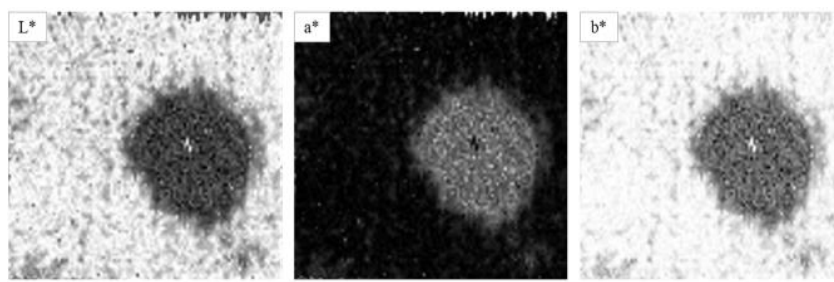

Figure 22. $\mathrm{L}^{*} \mathrm{a} * \mathrm{~b}$ images of carbon fiber face sheet Nomex sandwich samples at 5+20 $\mathrm{j}$ impact energy
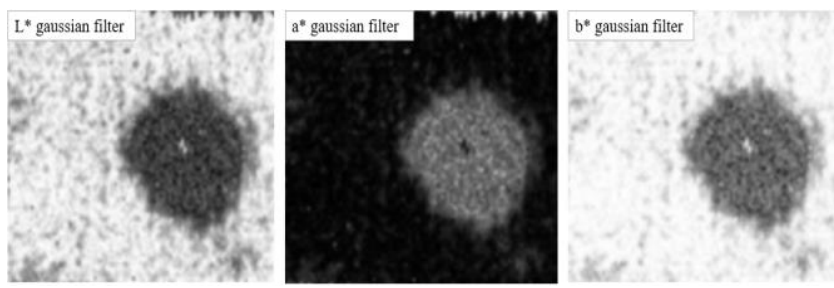

Figure 23. Gaussian images of carbon fiber face sheet Nomex sandwich samples at 5+20 j impact energy levels
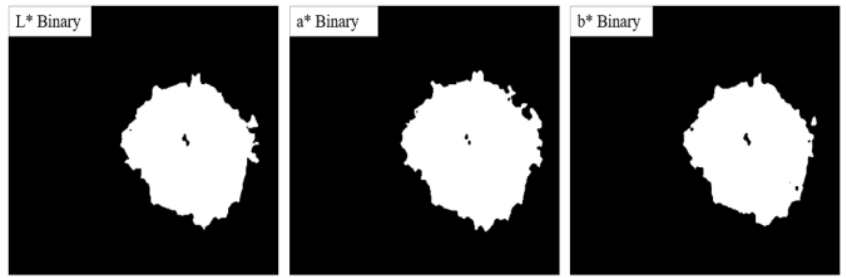

Figure 24. Binary images of carbon fiber face sheet Nomex sandwich samples at 5+20 j impact energy levels

The damage areas of the carbon fiber face sheet sandwich Nomex composites after image processing are given in the figure 25 .

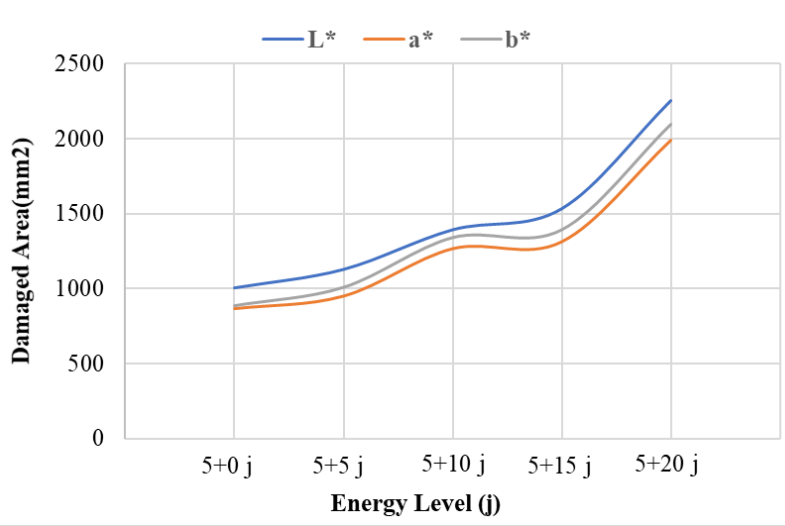

Figure 25. Damage areas obtained from carbon fiber face sheet sandwich Nomex composites by $1^{*}, a^{*}, b^{*}$ image processing method

When the $\mathrm{C}$-scan images of the composites which were subjected to low-velocity impact test at $5+0 \mathrm{j}, 5+5 \mathrm{j}, 5+10 \mathrm{j}, 5+15 \mathrm{j}$ and $5+20 \mathrm{j}$ energy levels are examined; Damage areas grew up with increasing impact energy levels. It was determined that the ultrasonic underwater C-scan method was successful in determining the visible or invisible damage of carbon fiber face sheet sandwich composites. When the table 1 . is examined, the damage areas at the $5+0 \mathrm{j}$ energy level determined as the initial energy level are approximately $1000 \mathrm{~mm}^{2}$ and below. Damage areas increased at the repeated energy level of $5+5 \mathrm{j}$, but no significant growth was detected. When the damage areas at the $5+10 \mathrm{j}$ energy level were examined, it was observed that more growth was observed than in the damaged areas at the $5+5 j$ energy level. The largest damaged area was observed at the $5+20$ $\mathrm{j}$ energy level. The amount of damage growth at this energy level was higher than the amount of damage growth at other energy levels. The strength of the carbon face sheet sandwich composites decreases as a result of the sudden growth of damaged areas at this energy level. It is known that delamination and fiber breakage damage are effective for sudden strength decreases in composite materials. However, damaged areas were formed in the upper face sheet of the sandwich composite material. When the damaged areas move towards the honeycomb and lower face layers, water fills the sandwich composite materials, and ultrasonic sound waves pass through these areas These regions are shown in red in C-scan images. When the C-scan images at all energy levels were examined, it was observed that the redcoloured damage areas were not formed.

\section{CONCLUSION}

Low-velocity impact tests were performed on carbon fiber face sheet Nomex sandwich composites at energy levels of $5+0 \mathrm{j}, 5+5$ $\mathrm{j}, 5+10 \mathrm{j}, 5+15 \mathrm{j}$, and $5+20 \mathrm{j}$.

To determine the amount of damage at the energy levels and also to observe the damage growth, first of all, low-velocity impact 
test at an energy level of $5 \mathrm{j}$ was applied to all composites, and the first damage was performed.

After the first damage was completed, low-velocity impact testing was performed with repeated and increasing energy levels. Before the impact tests, C-scan analysis was applied to all samples, and it was observed that there were no air voids and fiber matrix adhesion errors that may occur due to the production of composites.

Damage area growth rates were similar at $5+0 \mathrm{j}, 5+5 \mathrm{j}, 5+10 \mathrm{j}$ and $5+15 \mathrm{j}$ energy levels. At 5+20 energy level, the damage area growth rate was higher than at other energy levels. In this case, it was concluded that the damage formations differed at the energy level of $5+20 \mathrm{j}$.

The underwater ultrasonic C-scan method was found to be successful in detecting visible impact (VID) damage and barely visible (BVID) impact damage in sandwich composite materials. The absence of red-coloured areas in the damaged areas at the $5+20 \mathrm{j}$ energy level indicates that the impact surface was not completely broken or the other face sheet of the sandwich composite material was not damaged. If the sandwich composite material was completely damaged, there would be water ingress from the broken areas, which would be red areas in the C-scan analysis.

\section{Acknowledgements}

This research was supported by Selcuk University Scientific Research Unit (BAP) under project number 19301010.

\section{References}

[1] Q. Zhang et al., "Bioinspired engineering of honeycomb structureUsing nature to inspire human innovation," Progress in Materials Science, vol. 74, pp. 332-400, 2015.

[2] Z. Wang, "Recent advances in novel metallic honeycomb structure," Composites Part B: Engineering, vol. 166, pp. 731-741, 2019.

[3] Q. Zhang, X. Zhang, G. Lu, and D. Ruan, "Ballistic impact behaviors of aluminum alloy sandwich panels with honeycomb cores: An experimental study, "Journal of Sandwich Structures \& Materials, vol. 20, no. 7, pp. 861-884, 2018.

[4] D. Zhang, Q. Fei, J. Liu, D. Jiang, and Y. Li, "Crushing of vertexbased hierarchical honeycombs with triangular substructures," ThinWalled Structures, vol. 146, p. 106436, 2020.

[5] G. Sun, D. Chen, X. Huo, G. Zheng, and Q. Li, "Experimental and numerical studies on indentation and perforation characteristics of honeycomb sandwich panels," Composite Structures, vol. 184, pp. 110-124, 2018.

[6] D. Girolamo, H.-Y. Chang, and F.-G. Yuan, "Impact damage visualization in a honeycomb composite panel through laser inspection using zero-lag cross-correlation imaging condition," Ultrasonics, vol. 87, pp. 152-165, 2018.

[7] G. Sun, X. Huo, H. Wang, P. J. Hazell, and Q. Li, "On the structural parameters of honeycomb-core sandwich panels against low-velocity impact," Composites Part B: Engineering, vol. 216, p. 108881, 2021.

[8] M. D. Hill, "Damage resistance and tolerance investigation of carbon/epoxy skinned honeycomb sandwich panels," Loughborough University, 2007.

[9] W. He, L. Yao, X. Meng, G. Sun, D. Xie, and J. Liu, "Effect of structural parameters on low-velocity impact behavior of aluminum honeycomb sandwich structures with CFRP face sheets," ThinWalled Structures, vol. 137, pp. 411-432, 2019.

[10] V. Crupi, G. Epasto, and E. Guglielmino, "Comparison of aluminium sandwiches for lightweight ship structures: Honeycomb vs. foam," Marine structures, vol. 30, pp. 74-96, 2013.

[11]L. Piancastelli, L. Frizziero, G. Zanuccoli, N. Daidzic, and I. Rocchi, "A comparison between CFRP and 2195-FSW for aircraft structural designs," International Journal of Heat and Technology, vol. 31, no. 1, pp. 17-24, 2013.

[12] Girolamo, Donato, Huan-Yu Chang, and Fuh-Gwo Yuan. "Impact damage visualization in a honeycomb composite panel through laser inspection using zero-lag cross-correlation imaging condition." Ultrasonics 87 (2018): 152-165.
[13] J. Dong, B. Kim, A. Locquet, P. McKeon, N. Declercq, and D. Citrin, "Nondestructive evaluation of forced delamination in glass fiberreinforced composites by terahertz and ultrasonic waves," Composites Part B: Engineering, vol. 79, pp. 667-675, 2015.

[14]I. Papa, V. Lopresto, G. Simeoli, A. Langella, and P. Russo, "Ultrasonic damage investigation on woven jute/poly (lactic acid) composites subjected to low velocity impact," Composites Part B: Engineering, vol. 115, pp. 282-288, 2017.

[15]J. Sun et al., "Automated Quality Characterization for Composites Using Hybrid Ultrasonic Imaging Techniques," Research in Nondestructive Evaluation, vol. 30, no. 4, pp. 205-230, 2019.

[16] W. Post, M. Kersemans, I. Solodov, K. Van Den Abeele, S. J. Garcia, and S. Van Der Zwaag, "Non-destructive monitoring of delamination healing of a CFRP composite with a thermoplastic ionomer interlayer," Composites Part A: Applied Science and Manufacturing, vol. 101, pp. 243-253, 2017.

[17]J. Zhang and B. L. Fox, "Manufacturing influence on the delamination fracture behavior of the T800H/3900-2 carbon fiber reinforced polymer composites," Materials and manufacturing processes, vol. 22, no. 6, pp. 768-772, 2007.

[18] V. Dikshit, S. K. Bhudolia, and S. C. Joshi, "Multiscale polymer composites: A review of the interlaminar fracture toughness improvement," Fibers, vol. 5, no. 4, p. 38, 2017.

[19] Sato et al., "Clinical utility of capsule endoscopy with flexible spectral imaging color enhancement for diagnosis of small bowel lesions," Endoscopy international open, vol. 2, no. 02, pp. E80-E87, 2014.

[20]R. F. Waldemarin, P. C. Terra, L. R. Pinto, F. Faot, and G. B. Camacho, "Color change in acrylic resin processed in three ways after immersion in water, cola, coffee, mate and wine," Acta Odontológica Latinoamericana, vol. 26, no. 3, pp. 138-143, 2013.

[21]H. Kanzaki et al., "Linked color imaging (LCI), a novel imageenhanced endoscopy technology, emphasizes the color of early gastric cancer," Endoscopy international open, vol. 5, no. 10, pp. E1005-E1013, 2017. 